\title{
Analysis of Advanced Process Control Technology and Economic Assessment Improvement
}

\author{
Anukoon Asawachatroj ${ }^{1}$ and David Banjerdpongchai ${ }^{2 *}$ \\ 1 Technopreneurship and Innovation Management Program, Graduate School, Chulalongkorn University, \\ Bangkok 10330, Thailand \\ 2 Department of Electrical Engineering, Faculty of Engineering, Chulalongkorn University, Bangkok 10330, \\ Thailand \\ E-mail: bdavid@chula.ac.th*
}

\begin{abstract}
Advanced Process Control (APC) is considered for investment after the Distributed Control System (DCS) and Historian System of Industrial Automation and Control Systems (IACS) had been implemented. The benefits of APC application can be observed by economic assessment (EA), however the EA technique is still behind the development of APC technology. We review the literature on APC and EA and highlight the potential future development.
\end{abstract}

ENGINEERING JOURNAL Volume 16 Issue 4

Received 25 June 2012

Accepted 25 June 2012

Published 1 July 2012

Online at http://www.engj.org/

DOI:10.4186/ej.2012.16.4.1 
IACS has been the important solution for many complex industries such as Oil \& Gas, Petrochemical, Chemical, Pulp \& Paper, Cement, Power Plant industries. Currently, ANSI/ISA-99 Security Standards for Improved Security and Reliability [1] employs experienced control engineers to design the Plantwide System Architecture in IACS project. Based on IACS architecture depicted in Fig. 1, APC is the major technology of optimal control methods in Process Information Network. However, APC cannot be implemented as a standalone system without the prerequisite infrastructure of the Field Instrument Network (L1), Process Control Network (L2) such as DCS and Process Information Network (L3) such as Historian System. Applying an optimization approach to minimize the operating cost, APC will achieve the minimum cost via operation at most economic targets and limits. The benefits of APC consist of increased throughput, increased profitability by improving process stability, better product quality, decreased cost of operation, and flexibility in operating condition [2].

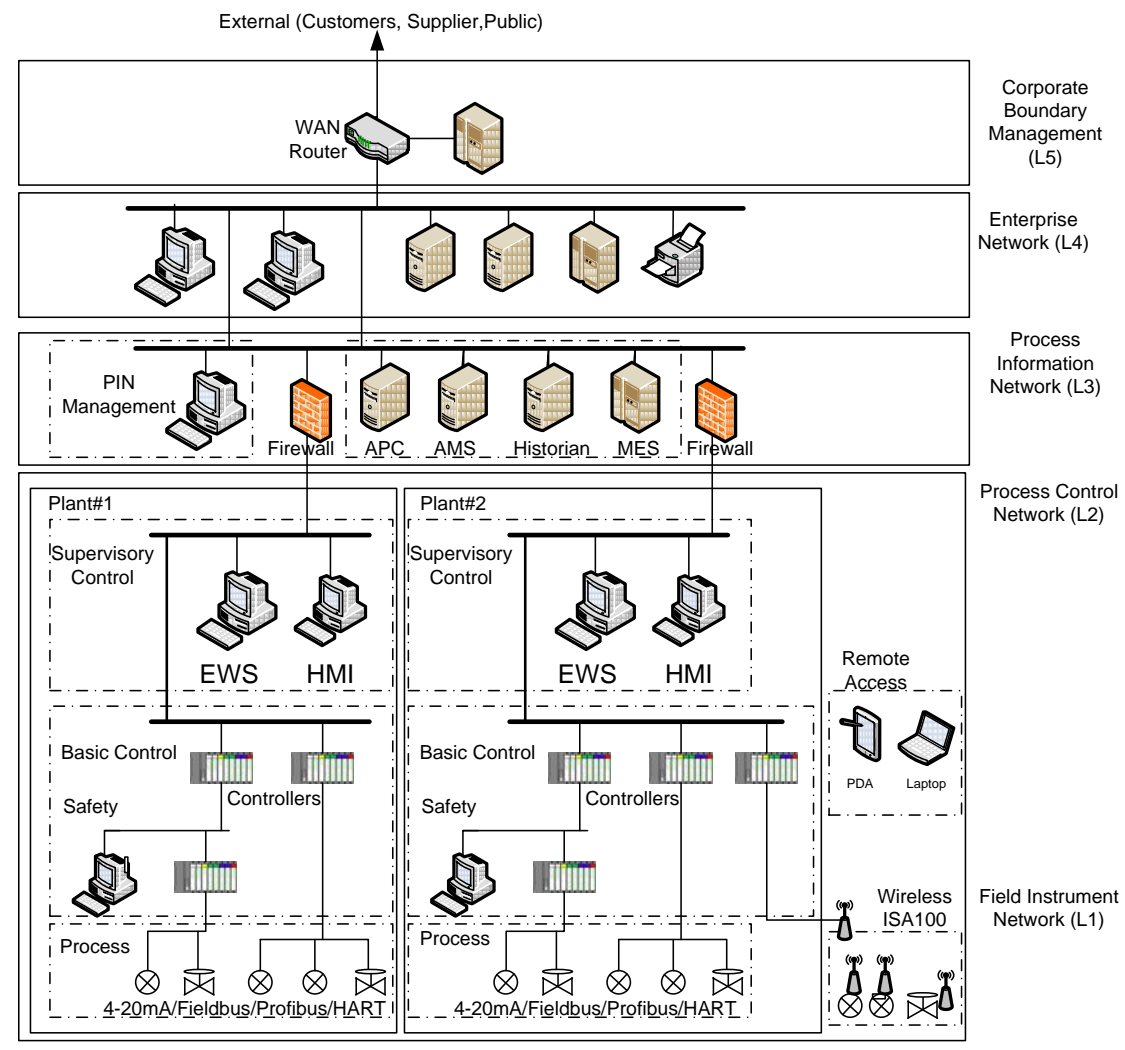

Fig.1. Example of IACS architecture in compliance with ANSI/ISA-99 Security Standards for Improved Security and Reliability [1].

APC has been categorized into several terms. The dominant design in APC has adopted to use Model Predictive Control (MPC). Hence, for control engineering community, APC is equivalent to MPC. Nevertheless, modern computer technology can provide other controllers such as Fuzzy Logic Control (FLC), Neural Network (NN), Nonlinear and Adaptive controllers, Predictive Functional Control (PFC), Active Disturbance Rejection Control (ADRC), Generic Model Control (GMC), Process-Model Based Control (PMBC), Internal Model Control (IMC) [3]. These controllers are considered among APC technology as well. Choosing the appropriate tool from the process control knowledge is an important step toward the decision making to the IACS project investment which has to align with business strategy. APC, especially MPC, has been around for over 20 years and is widely used in the heavy industries. Over the past five years, the number of APC applications worldwide was estimated more than 6,000 and growing steadily [4]. To make a decision whether APC should be roll-out on top of DCS platform is important. This is because the investment cost of APC can start from hundred thousands of USD to millions of USD. Economic assessment is a key tool to estimate the cost and benefits from the project. Then applying financial analysis to justify whether the business drivers of process control is worth spending. 
Over recent years, APC has been further refined such as an integration of nonlinear models to improve control strategy and optimize process performance [5], coordinate optimization of multiple units [6], performance monitoring tools while keeping the controller running to identify which models are problematic [7]. While IACS has been continuously improved through the past decades, the EA methodology that derives from APC and advanced solutions still remains the same such as estimation of variance reduction [8], cost and benefit study [9]. We review the literature on APC and EA [3, 7-13] and highlight the trends of APC and EA methodology. The survey results are summarized in Table 1 . In addition to listing the trends of APC technology and EA improvement, we prioritize the importance and impact based on the observed frequency in the literature. These trends can be addressed for future interdisciplinary research including chemical engineering, control engineering, financial engineering, expert system (ES) and innovation management. Many industries in Thailand such as Oil \& Gas, Petrochemical and Chemical industries have been implemented APC. The future work requires intensive research from both academic and industrial sides. Hence, the university-industry collaboration can serve as an effective means to deploy both APC and the new EA methodology. The collaborative topics can be selected for pilot test and the developed tool can be assessed and improved before it can be commercialized.

Table 1. Summary of the potential APC technology and EA improvement.

\begin{tabular}{|c|c|c|}
\hline No. & APC Technology & EA Improvement \\
\hline 1 & $\begin{array}{l}\text { Composite view of next generation for MPC such as } \\
\text { Basic controller formulation, Adaptive MPC, Robust } \\
\text { MPC, Nonlinear MPC for multiple objective functions, } \\
\text { Automation of the hierarchal structure. } \\
{[3,9,10,11,13]}\end{array}$ & $\begin{array}{l}\text { The integration of assessment of APC with higher } \\
\text { and lower level applications such as real time } \\
\text { optimization (RTO), planning and scheduling } \\
\text { systems }[3,9,10]\end{array}$ \\
\hline 2 & $\begin{array}{l}\text { Detection and diagnosis of control performance } \\
\text { deterioration for normal and abnormal event. } \\
{[3,7,11,12]}\end{array}$ & $\begin{array}{l}\text { Use economic uncertainty to address control } \\
\text { action. Adoption of the alternative financial tools } \\
\text { for EA. }[3,8,9]\end{array}$ \\
\hline 3 & $\begin{array}{l}\text { MPC tuning by integrating information from historical } \\
\text { data, test data, laboratory analysis as feedback action } \\
\text { when inferential techniques use laboratory data for } \\
\text { updates. }[3,11,12]\end{array}$ & $\begin{array}{l}\text { Combined cost and benefit analysis for APC and } \\
\text { RTO. }[3,9,10]\end{array}$ \\
\hline 4 & $\begin{array}{l}\text { Modeling framework for control which integrates both } \\
\text { empirical and fundamental model. }[3,11,13]\end{array}$ & $\begin{array}{l}\text { Integration of expert knowledge into advanced } \\
\text { control solutions and interface for operators and } \\
\text { engineers such as recommender system. }[3,9,10]\end{array}$ \\
\hline 5 & $\begin{array}{l}\text { Improvement of robust, accurate, in-process cost } \\
\text { accounting systems to determine the value of } \\
\text { intermediate and final products. }[3,11]\end{array}$ & $\begin{array}{l}\text { Utilize the benefits from previous application } \\
\text { audits on a per unit per situation basis to facilitate } \\
\text { estimation of economic benefit of new project. } \\
{[3,9,11]}\end{array}$ \\
\hline 6 & Improved disturbance estimators. [11] & $\begin{array}{l}\text { Evaluation of economic impact of model } \\
\text { degradation. }[3,7,11]\end{array}$ \\
\hline 7 & $\begin{array}{l}\text { Shifting of FLC and ES marketing from feedback } \\
\text { control to supervisory applications. [3] }\end{array}$ & $\begin{array}{l}\text { Continuous monitoring of economic benefit, total } \\
\text { and for each loop. }[3,9]\end{array}$ \\
\hline 8 & Development of Cascaded and distributed MPC. [3] & Cost and benefit analysis of MPC. [3,9] \\
\hline 9 & $\begin{array}{l}\text { Control of perceived situations from visual, acoustic, } \\
\text { sniffer diagnosis of phenomena. [3] }\end{array}$ & $\begin{array}{l}\text { Calculation of lost opportunity cost from } \\
\text { model degradation, benefits from an increased } \\
\text { asset lifetime and expected performance without } \\
\text { APC under the current operating scenario. [9] }\end{array}$ \\
\hline 10 & $\begin{array}{l}\text { Autonomous health monitoring for both process and } \\
\text { control system. [3] }\end{array}$ & $\begin{array}{l}\text { Use base case estimation for missing or wrong } \\
\text { data. [9] }\end{array}$ \\
\hline
\end{tabular}


In conclusion, we review the literature involved in APC technology and EA improvement and identify the opportunity of the future works. The university-industry collaboration is suggested to deploy APC and the new EA methodology to ensure the success of the APC application to Thailand industrial sectors. As a collaborative example, an innovative recommender system with EA framework was proposed in [14]. Three major aspects, namely, technology, economics \& finance, and innovation management, are integrated into the selection criteria of APC. The proposed recommender system aims to provide a prudential guidance along the business life cycle whether the selected APC will be worthwhile for IACS investment.

\section{Acknowledgement}

We gratefully acknowledge the support from the $90^{\text {th }}$ Anniversary of Chulalongkorn University Fund (Ratchadaphiseksomphot Endowment Fund).

\section{References}

[1] ISA99 Security Guidelines and User Resources for Industrial Automation and Control Systems, 3rd ed., ISA, Research Triangle Park, NC, USA, 2009.

[2] Honeywell Process Solutions, "Optimization white paper," Honeywell, Phoenix, AZ, USA, Rep. WP0602ENG, 2009.

[3] R. R. Rhinehart, M. L. Darby, and H. L. Wade, "Choosing advanced control," IS A Transactions, vol. 50, pp. 2-10, 2011.

[4] W. M. Canney, "Are you getting the full benefit from your advanced process control system?," Hydrocarbon Processing, vol. 84, no. 6, pp. 55-58, 2005.

[5] M. Heidarinejad, J. Liu, and P. D. Christofides, "Economic model predictive control of nonlinear process systems using Lyapunov techniques," AIChE Journal, vol. 58, no. 3, pp. 855-870, 2012.

[6] E. M. B. Aske, S. Strand, and S. Skogestad, "Coordinator MPC for maximizing plant throughput," Computers and Chemical Engineering, vol. 32, pp. 195-204, 2008.

[7] R. S. Patwardhan and B. McIntyre, "Monitoring, best practices maintain APC applications," Oil \& Gas Journal, vol. 106, no. 30, pp.46-53, 2008.

[8] C. Zhao, H. Su, Y. Gu, and J. Chu, "A pragmatic approach for assessing the economic performance of model predictive control systems and its industrial application," Journal of Chemical Engineering, vol. 17, no. 2, pp. 241-250, 2009.

[9] M. Bauer and I. K. Craig, "Economic assessment of advanced process control-a survey and framework," Journal of Process Control, vol. 18, pp. 2-18, 2008.

[10] S. J. Qin and T. A. Badgwell, "A survey of industrial model predictive control technology," Control Engineering Practice, vol. 11, pp. 733-764, 2003.

[11] M. L. Darby, M. Harmse, and M. Nikolaou, "MPC: current practice and challenges," in Proc. of the $7^{\text {th }}$ IF AC International Symposium on Advanced Control and Chemical Processes, Turkey, 2009.

[12] M. Jelali, "An overview of control performance assessment technology and industrial applications," Control Engineering Practice, vol. 14, pp. 441 - 466, 2006.

[13] J. R. Ford. (2008) APC: A status report. Maverick technologies. [Online]. Available: www.mavtechglobal.com/shared/pdf/wp_apc_statusReport.pdf

[14] A. Asawachatroj and D. Banjerdpongchai, "Design of innovative recommender system for economic assessment with application to advanced process control," in Proc. of the 8th ECTI Conference, Thailand, 2011, pp. 581-584. 